\title{
¿PERÍFRASIS CUASISINÓNIMAS? UNA REGRESIÓN LOGÍSTICA APLICADA A LAS INCOATIVAS EXPRESADAS CON PONERSE Y METERSE
}

\author{
¿NEAR-SYNONYMOUS PERIPHRASES? A LOGISTIC REGRESSION APPLIED \\ TO INCHOATIVES EXPRESSED WITH PONERSE AND METERSE
}

\author{
MARIE COMER \\ Universidad de Gante \\ Marie.Comer@Ugent.be \\ https://orcid.org/0000-0001-6806-7576
}

Recibido: 27/06/2019

Aceptado: 30/04/2020

\begin{abstract}
Resumen
El presente artículo propone un estudio de corpus sobre dos construcciones incoativas cuasisinónimas en español con ponerse y meterse ("to put"). Partiendo del principio universal de la economía lingüística, el documento pretende identificar empíricamente las variables que potencialmente determinan la elección del hablante entre los dos verbos a la hora de expresar un evento incoativo. Se investiga si la elección depende de un conjunto de variables relacionadas con el sujeto, el auxiliar, el infinitivo y/o la naturaleza de la propia perífrasis. La diferencia entre los cuasisinónimos está determinada principalmente por el grado de asociación entre el auxiliar y el infinitivo, la connotación (negativa vs. neutra) subyacente de la construcción, el tipo de oración (afirmativa vs. negativa), el as-
\end{abstract}

\begin{abstract}
The present article proposes a corpus-based study of two near-synonymous inchoative constructions in Spanish with ponerse and meterse ('to put'). Starting from the universal principle of linguistic economy, the paper aims to empirically identify potentially influencing variables that determine the native speaker's choice between the two verbs when expressing an inchoative event. It is investigated whether and to what extent the choice is governed by a set of variables related to the subject, the auxiliary, the infinitive and/or the nature of the periphrasis itself. The difference between the near-synonyms is shown to be mainly determined by the degree of association between the auxiliary and the infinitive, the (negative vs neutral) connotation underlying the construction, the sentence
\end{abstract}

Para citar este artículo / To cite this article: Comer, Marie (2020). ¿Perífrasis cuasisinónimas? Una regresión logística aplicada a las incoativas expresadas con ponerse y meterse . ELUA, 34: 9-38. https://doi.org/10.14198/ELUA2020.34.1

Enlace / Link: https://doi.org/10.14198/ELUA2020.34.1 
pecto gramatical del auxiliar y el género textual en el que aparece la perífrasis.

PALABRAS CLAVE: perífrasis incoativas, ponerse, meterse, regresión logística, cuasisinonimia. type (affirmative vs. negative), the grammatical aspect of the auxiliary and the textual genre in which the periphrasis appears.

KEYWORDS: inchoative periphrasis, ponerse, meterse, logistic regression, near-synonymy.

\section{INTRODUCCIÓN}

Una perífrasis verbal se define tradicionalmente como "la unión de dos o más verbos que sintácticamente constituyen un solo núcleo del predicado" (Gómez Torrego 1988: 9), unidos entre sí con o sin un nexo preposicional (Torrego 1988, 1999; Yllera 1980; RAE/ASALE 2009; Zieliński 2014: 19-20). En general, en la literatura que trata de las perífrasis verbales en las lenguas romances hoy en día existen abundantes estudios dedicados a las perífrasis aspectuales incoativas, a las que pertenecen ponerse y meterse seguidos de infinitivo (vid. Gómez Torrego 1988; Gómez Manzano 1992; García González 1992; Peeters 1993; Saunier 1996, 1999; Lamiroy 1999; Llorente Vigil 1999; Fogsgaard 2001, 2002; Verroens 2011; Aparicio, Coll-Florit \& Castellón 2014; Aparicio 2016, por citar algunos). Ambas construcciones con ponerse y meterse aparecen listadas en el Diccionario de Perifrasis Verbales de Carrasco Gutiérrez et al. (2006: 202-205, 218-223) y corresponden a la definición de perífrasis como una categoría radial propuesta por Garachana (2017: 36), al ser construcciones (i) de significado procedimental unitario (no composicional), (ii) en las que ninguna parte es conmutable por otro elemento, y (iii) cuya selección de argumentos depende del predicado verbal (constituido por la unión del auxiliar y del auxiliado). ${ }^{1}$ Sin embargo, la literatura previa ha prestado especial atención al estudio de ponerse (desatendiendo a meterse) y, además, se ha centrado sobre todo en las similitudes de las dos perífrasis, no tanto en sus diferencias. Las restricciones semánticas que se alegan para caracterizar al sujeto y al infinitivo a primera vista parecen solaparse y ser válidas tanto para [ponerse $a+\mathrm{INF}$ ] como para [meterse $a+\mathrm{INF}]$. Así, la literatura asume que ambos verbos tienden a rechazar sistemáticamente infinitivos de estado (1a-c), y que ambos necesariamente requieren un esfuerzo, una decisión o una intencionalidad por parte de un sujeto-agente que comienza la acción, de ahí la agramaticalidad de ejemplos como (2).

(1) a. *Se pone a ser de noche. [Carrasco Gutiérrez et al. 2006: 222]

b. *Jorge pone la botella a estar fresca. [Lamiroy 1991: 133]

c. *Se resolvían en sus asientos porque se metían a tener hambre. [Carrasco Gutiérrez et al. 2006: 203]

(2) Después de casarse, *se puso a engordar sin darse cuenta. [Carrasco Gutiérrez et al. 2006: 221]

1 No obstante, este segundo criterio es objeto de debate. Gómez Torrego (1988: 111), por ejemplo, alega que el infinitivo de meterse es conmutable por un pronombre (Juan se metió a vender coches: Juan se metió a eso), por lo que no cumple con uno de los criterios definitorios establecidos por varios autores (vid. Gómez Torrego 1988; García Fernández 2012; Carrasco Gutiérrez et al. 2006). Otro tanto sucede con ponerse (Se puso a leer el periódico: Se puso a eso). Sin embargo, aunque todos consideran que [ponerse $a+\mathrm{INF}]$ es una auténtica perífrasis verbal (RAE/ASALE 2009; Lluïsa Hernanz 1999: 2201; Gómez Torrego 1999: 3373-3374), no todos están de acuerdo en el carácter perifrástico de [meterse a $+\mathrm{INF}]$. Por tanto, el criterio de la conmutación nominal y pronominal no parece ser un criterio coherente. 
(3) Aun así, haciendo abstracción de las preferencias que ponerse y meterse tienen en común, destacan también diferencias entre las dos construcciones. Así por ejemplo, cuando funcionan como auxiliares incoativos, observamos que ponerse y meterse algunas veces pueden alternar (como en 3a-3b), pero otras veces no transmiten los mismos matices (3c), como veremos más adelante: se mete vs. se pone a solucionar lo que no es de su competencia. De ahí se deduce que se trata de perífrasis cuasisinónimas cuya intersección común es solo parcial:

(4) a. Yo me senté en una silla -ese día las sillas estaban cojas- y me puse a pensar en el abuelo.

[CORPES XXI 1]

b. Declaraciones del Cardenal Cipriani: "Un ministro de salud que reparte píldoras abortivas tiene que irse a su casa". Se ve que el hombre no se ha enterado que en este país el gobierno es (o debería ser laico). No se meta a predicar en mis colegios y yo no me meteré a pensar en su iglesia. [Sketch engine]

c. Yo creo que el Ayuntamiento de Aranda tiene bastantes más problemas en la ciudad para meterse a solucionar los que no son de su competencia. [Sketch engine]

A la luz de estas constataciones, el objetivo de esta contribución será aclarar y averiguar, por medio de una profunda investigación empírica, las semejanzas y divergencias más destacadas en el uso de estos dos cuasisinónimos, tanto en el plano semántico como sintáctico.

Pocos estudios lingüísticos se han volcado en este tema y, como se ha dicho más arriba, todas las obras existentes se basan en ejemplos introspectivos y construidos ad hoc. Falta, por tanto, un enfoque empírico e integrador que dé cuenta del comportamiento semánticosintáctico de estos verbos en su uso real y que permita corroborar o no las intuiciones previas por medio de resultados cuantitativos y fiables, así como revelar tendencias subyacentes. Nuestro estudio estará marcado por un enfoque no solamente cualitativo, sino también cuantitativo y estadístico.

\section{CORPUS Y METODOLOGÍA}

Para el presente estudio, se ha compilado y anotado manualmente un corpus. En concreto, se ha extraído la totalidad de los ejemplos incoativos de poner y meter presentes en cuatro corpus diferentes, que incluyen tanto textos orales como escritos (de ficción y de no ficción): CORPES XXI, Corlec, CoralRom y Sketch engine. Todos los ejemplos provienen del siglo XXI. ${ }^{2}$ El proceso de búsqueda se ha limitado a los datos procedentes del español europeo. Como se puede ver en la Tabla 1, el total de ejemplos en el que se basará la regresión logística se eleva a 3646. Salta a la vista la discrepancia considerable entre el número de ejemplos incoativos encontrados con ponerse y con meterse.

2 Los ejemplos citados de los corpus CORPES XXI, Corlec y CoralRom se encuentran numerados y con su referencia exacta en la bibliografía. Por el contrario, Sketch engine, un corpus en línea que incluye ejemplos escritos contemporáneos provenientes de foros, blogs y sitios en Internet, no señala el año exacto de los ejemplos, pero todos ellos provienen del siglo XXI. Solo hemos seleccionado los usos incoativos del español peninsular como macro-variedad (i.e. de sitios cuyo enlace se termina en.es). 


\begin{tabular}{|c|c|}
\hline ponerse & meterse \\
\hline 2925 & 721 \\
\hline \multicolumn{2}{|c|}{3646} \\
\hline
\end{tabular}

Tabla 1. Frecuencia de los dos verbos para el estudio de caso

Cabe añadir que el presente corpus solo contiene las perífrasis incoativas prototípicas de ponerse y meterse, que corresponden a la definición de Garachana (2017: 64-65) propuesta arriba. Por tanto, se han excluido del corpus los ejemplos incoativos de tipo (4), que se sitúan a medio camino entre el uso locativo y el uso incoativo, al presentar la estructura [Aux - CLOC - (a + INF)].

(4) Se puede tener muy buen ojo clínico, como el que tienen muchos médicos, pero no poseer la capacidad para meterse en un laboratorio a investigar. [CORPES XXI 2]

Son ejemplos en los que el evento de 'ponerse o meterse en un lugar a empezar una acción' equivale al de 'ponerse o meterse en este sitio para hacer algo'. En estos casos, una parte de la construcción es conmutable por otro elemento y el significado del todo no es unitario, sino composicional: a una oración de significado locativo se suma una subordinada de finalidad encabezada por para.

La técnica de regresión logística (RL) constituye el método de estadística confirmatoria más adecuado para detectar las diferencias de uso entre ponerse y meterse. Conlleva una variable dependiente binaria (llamada response variable) y una serie de variables independientes o predictoras (predictor variables). El método permite analizar con precisión la relación entre ambos, al medir el impacto que tiene determinada variable predictora en la variable dependiente cuando concurren otras variables predictoras (Divjak 2010: 319; Fischer 2010: 50).

Dentro del marco de la Lingüística Cognitiva, la RL binaria resulta particularmente eficaz en los estudios dedicados a la cuasisinonimia léxica, la alternancia de construcciones sintácticas o la polisemia (vid. Grondelaers, Speelman \& Geeraerts 2002; Heylen 2005; Arppe 2008; Glynn 2010; Szmrecsanyi 2010; Speelman \& Geeraerts 2009; Klavan 2014; Levshina 2015). En estos casos, la variable dependiente adquiere dos posibles valores. Puede por ejemplo tratarse de verbos (p.ej. doen 'hacer' vs. laten 'dejar') o sustantivos (p.ej. bike vs. bicycle), pero también de alternancias fonológicas (p.ej. la realización o no de la $r$ final en palabras inglesas) o de construcciones enteras (p.ej. la alternancia del dativo: he gave me money vs. he gave money to me) (Speelman 2014: 489). La RL se utiliza para sopesar la influencia de ciertas variables predictoras en esta elección y para identificar aquellas variables que mejor predicen la elección por uno u otro miembro lingüístico. Estos predictores pueden ser catégoricos o numéricos, lo que les permite representar un amplio abanico de características morfosintácticas, semánticas o pragmáticas de la pareja lingüística estudiada.

Así pues, se intentará descubrir en el presente estudio, por medio de una RL binaria, qué factores incrementan la probabilidad de que meterse o ponerse aparezcan en un determinado contexto incoativo. El objetivo será identificar aquellas variables que favorecen el empleo de uno u otro verbo en su uso perifrástico actual. ${ }^{3}$

3 Para una explicación más detallada de la técnica, remitimos a las obras de referencia de Speelman \& Geeraerts (2009), Speelman (2014) o Baayen (2008). 


\section{VARIABLES PREDICTORAS DEL MODELO}

Pasamos a la presentación de las variables predictoras que se retomarán en el modelo estadístico. Distinguimos una variable predictora morfosintáctica (analizada en 3.1) y nueve variables semánticas (3.2). Los parámetros semánticos se subdividen en diferentes categorías en función de si se relacionan con el sujeto (3.2.1), el auxiliar (3.2.2), el infinitivo (3.2.3) o la naturaleza de la perífrasis entera (3.2.4).

\subsection{Factores morfosintácticos: grado de asociación}

El primer parámetro, a saber, el grado de asociación entre el auxiliar y su(s) infinitivo(s), se basa en la literatura. Siguiendo a Bybee \& Torres Cacoullos (2009) y Torres Cacoullos (2000), en sus estudios sobre las construcciones de gerundio [p.ej. estar $V$-ndo], tal criterio supone dos posibilidades: la unión del auxiliar con un único gerundio (p.ej. estoy comiendo y estoy bebiendo) o su unión con varios gerundios coordinados a la vez (estoy comiendo y bebiendo). En general, se asume que una rección de múltiples gerundios por un solo auxiliar conlleva un grado de asociación más bajo. Así, Torres Cacoullos (2000: 36) afirma:

What is important is that in multiple gerund constructions, there is not a one-to-one relationship between an auxiliary and an -ndo form, since the same auxiliary appears to be in construction with two or more gerunds, each one vying for a connection with the auxiliary. The lack of a one-to-one relationship between the auxiliary and the -ndo form detracts from their identification as a fused unit. [Torres Cacoullos 2000: 36]

De este modo, la presencia de uno o más gerundios regidos permite medir el grado de fusión de las construcciones, y lo mismo vale para las perífrasis de infinitivo aquí estudiadas. Así, aplicando el parámetro a ponerse y meterse, una múltiple rección del infinitivo (5) implicaría un grado de asociación más bajo, puesto que la vinculación entre el auxiliar y varios infinitivos coordinados no es muy estrecha. Por el contrario, cuando un auxiliar incide sobre un solo infinitivo (6), existe una cohesión más fuerte entre ambos constituyentes, de modo que será más elevado su grado de asociación y, con ello, su grado de fusión.

(5) A continuación, se pone a abrir cajones y a registrar sus contenidos. [CORPES XXI 3]

(6) Quise distraerme con la tele. Me puse a buscar el mando a distancia. [CORPES XXI 4]

Además, el auxiliar en (6) tiene un alcance estructural (o structural scope) más reducido que el auxiliar en (5), donde aparece con dos formas infinitas. La relación entre un auxiliar y un solo infinitivo refleja entonces - de acuerdo con el criterio de condensación de Lehmann (1995) - un estadio de gramaticalización más avanzado. ${ }^{4}$ En cambio, una múltiple rección del infinitivo implicaría lo contrario: el auxiliar tiene un alcance estructural más amplio y, en consecuencia, un grado de gramaticalización más bajo.

Todos los ejemplos del corpus se han etiquetado en función de su aparición con uno o varios (dos o más) infinitivos. La Tabla 2 presenta los porcentajes absolutos y relativos del

4 Sin embargo, señalamos, siguiendo a Traugott (2015), que la gramaticalización de las perífrasis verbales afecta a la construcción al completo y no solo al auxiliar. 
parámetro. Lo más frecuente para ambos verbos es la construcción con un solo infinitivo, pero el grado de asociación de meterse es más bajo que el de ponerse (un 16,4\% de infinitivos múltiples con aquel, frente al 3\% con este). A primera vista, meterse presenta entonces un alcance estructural más amplio y, por tanto, un grado de gramaticalización menor que ponerse.

\begin{tabular}{|c|c|c|c|c|}
\hline \multirow{2}{*}{} & \multicolumn{2}{|c|}{ ponerse } & \multicolumn{2}{c|}{ meterse } \\
\cline { 2 - 5 } & $\#$ & $\mathbf{\%}$ & $\#$ & $\mathbf{\%}$ \\
\hline 1_INF & 2837 & $\mathbf{9 7}$ & 603 & $\mathbf{8 3 , 6}$ \\
\hline Múltiples_INF & 88 & 3 & 118 & 16,4 \\
\hline Total & $\mathbf{2 9 2 5}$ & $\mathbf{1 0 0}$ & $\mathbf{7 2 1}$ & $\mathbf{1 0 0}$ \\
\hline
\end{tabular}

$\mathrm{X}^{2}=119,91, \mathrm{df}=1, \mathrm{p}=2,200 \mathrm{e}-16$

Tabla 2. Grado de asociación

\subsection{Factores semánticos}

\subsubsection{Factores relacionados con el sujeto: animacidad}

En lo tocante a la animacidad del sujeto o $\mathrm{SN}_{1}$, se han analizado los ejemplos en función de la capacidad o no del sujeto para provocar un cambio de estado por sí mismo. Es decir, se ha tenido en cuenta si la naturaleza semántica del $\mathrm{SN}_{1}$ es animada (humanos, animales), inanimada (concreta y abstracta) o si se trata de una oración impersonal.

Los nombres colectivos se han clasificado según se refieran a un conjunto de seres animados (p.ej. la muchedumbre) o a entidades inanimadas (p.ej. la mercancía). Se ha determinado la índole semántica tanto de sujetos explícitos (7) como implícitos (sujetos nulos o tácitos) (8). Asimismo, se ha determinado la naturaleza semántica de sujetos asociados tanto con un auxiliar conjugado (7-8) como no conjugado (9), aun cuando, estrictamente hablando, las formas de infinitivo no poseen un sujeto sintáctico. En oraciones con sujetos tácitos o auxiliares no conjugados, es el contexto lingüístico el que permite deducir si se trata de un participante animado o inanimado. Así, (8) y (9) se han clasificado ambos como ejemplos con un $\mathrm{SN}_{1}$ animado. Los enunciados con un sujeto impersonal (10) se han categorizado por separado, como un tercer grupo, junto a los animados y los inanimados. Esta categoría 'impersonal' se aplica a los predicados que denotan fenómenos naturales (meteorológicos), como (ponerse a) llover, nevar, granizar, amanecer, atardecer, etc.

(7) La doctora Rutheford-Klein se puso a auscultar el pecho del paciente, luego se levantó y salió de la habitación para regresar de inmediato con un inhalador para el asma. [CORPES XXI 5]

(8) Abrieron las ventanas y $[\varnothing]$ se pusieron a respirar con fruición aquel aire incierto de comienzos del verano. [CORPES XXI 6]

(9) El profesor ferrolano Jesús Neira acaba de recibir la Gran Cruz al Mérito Civil, por haberse metido a ayudar a una mujer que estaba siendo maltratada. [Sketch engine] 
(10) A dos manzanas de su casa [Ø] se puso a diluviar. [CORPES XXI 7]

El resultado se resume en la Tabla 3, que comporta tres regresores o niveles de análisis: [animado], [inanimado] e [impersonal].

\begin{tabular}{|c|c|c|c|c|}
\hline \multirow{2}{*}{} & \multicolumn{2}{|c|}{ ponerse } & \multicolumn{2}{c|}{ meterse } \\
\cline { 2 - 5 } & $\#$ & $\mathbf{\%}$ & $\#$ & $\mathbf{\%}$ \\
\hline animado & 2791 & $\mathbf{9 5 , 4}$ & 712 & $\mathbf{9 8 , 8}$ \\
\hline inanimado & 114 & 3,9 & 9 & 1,2 \\
\hline impersonal & 20 & 0,7 & 0 & 0 \\
\hline Total & $\mathbf{2 9 2 5}$ & $\mathbf{1 0 0}$ & $\mathbf{7 2 1}$ & $\mathbf{1 0 0}$ \\
\hline \multicolumn{3}{|c}{$\mathrm{X}_{2}=35,369, \mathrm{df}=2, \mathrm{p}=2,088 \mathrm{e}-08$}
\end{tabular}

Tabla 3. Animacidad del sujeto

Con ambos verbos, la expansión semántica de los sujetos es casi nula. El paradigma de ponerse y meterse está ampliamente dominado por la presencia de sujetos animados (humanos y animales). Los sujetos inanimados e impersonales, en cambio, se presentan solo muy pocas veces (en el caso de ponerse) o son completamente ausentes (p.ej. los impersonales con meterse).

\subsubsection{Factores relacionados con el auxiliar: aspecto gramatical}

Por otro lado, resulta interesante investigar hasta qué punto las perífrasis con ponerse y meterse difieren en cuanto al aspecto verbal del auxiliar. Los ejemplos se han dividido en dos clases: [imperfectivo] o [perfectivo]. El aspecto imperfectivo comprende todas las perífrasis incoativas en las que el auxiliar aparece en un tiempo simple, menos el pretérito perfecto simple (p.ej. pone, ponía). En cambio, el aspecto perfectivo se reserva para las perífrasis cuyo auxiliar se conjuga en un tiempo compuesto o en pretérito perfecto simple (p.ej. he puesto, puse) (Gili Gaya 1961; Rojo 1990: 23).

En general, se acepta que los tiempos perfectivos favorecen la conceptualización de una situación como un todo, sin distinguir las diferentes etapas que la componen; se percibe así la situación en su totalidad, sin recurrir a su constitución temporal interna. En cambio, con un tiempo imperfectivo el enfoque radica precisamente en la estructura interna de la situación (Comrie 1976: 16; Lúcia Esteves 2004: 20). La oposición básica en el ámbito aspectual se explica entonces por la presencia (imperfectivo) o ausencia (perfectivo) de una referencia explícita a la estructura temporal interna del evento (Comrie 1976: 21, 24). ${ }^{5}$

5 Como consecuencia de esta caracterización, se ha asociado el aspecto perfectivo con un evento puntual o momentáneo, y con situaciones de corta o limitada duración, debido a que no refleja la estructura temporal interna de una situación, sino que la reduce a un solo 'punto'. El aspecto imperfectivo, por su parte, se ha asociado con una lectura más durativa del evento. Sin embargo, esta opinión no es compartida por todos los lingüistas. Así, Comrie (1976: 16-17), Rojo (1990: 33), Slawomirski (1983: 100) y Lúcia Esteves (2004: 20-21), entre otros, rechazan el carácter puntual o durativo como rasgo pertinente de la oposición entre llegué y llegaba, por ejemplo, o se puso a llover y se ponía a llover. Lo tachan de 'impropiedad', al considerar que ambos aspectos pueden en 
De este modo, en (11a) se conceptualizarían las fases temporales internas de la acción de hablar, pero no ocurriría lo mismo en (11b).

(11) a. Pero tus niños se ponen a hablar en catalán entre ellos cuando yo estoy delante, le dije. Ay, Rosario, también lo hacen delante de mí, son niños. [CORPES XXI 8] b. Al anochecer, Laura acudió al Corte Inglés de Nuevos Ministerios, a la sección de sábanas y toallas. Ella y Sedal se pusieron a hablar junto a las cortinas de baño. [CORPES XXI 9]

Obsérvense los porcentajes obtenidos del análisis en la Tabla 4.

\begin{tabular}{|c|c|c|c|c|}
\hline \multirow{2}{*}{} & \multicolumn{2}{|c|}{ ponerse } & \multicolumn{2}{c|}{ meterse } \\
\cline { 2 - 5 } & $\#$ & $\mathbf{\%}$ & $\#$ & $\mathbf{\%}$ \\
\hline perfectivo & 1390 & 47,5 & 184 & 25,5 \\
\hline imperfectivo & 1535 & 52,5 & 537 & $\mathbf{7 4 , 5}$ \\
\hline Total & $\mathbf{2 9 2 5}$ & $\mathbf{1 0 0}$ & $\mathbf{7 2 1}$ & $\mathbf{1 0 0}$ \\
\hline
\end{tabular}

$\mathrm{X}_{2}=114, \mathrm{df}=1, \mathrm{p}=0,000$

Tabla 4. Aspecto gramatical

Destaca a primera vista una diferencia importante entre los dos verbos: meterse parece decantarse mayoritariamente por los tiempos imperfectivos, mientras que con ponerse el aspecto gramatical presenta más equilibrio en el corpus.

\subsubsection{Factores relacionados con el infinitivo}

\subsubsection{Dinamicidad del infinitivo}

La cuarta variable es la naturaleza del infinitivo que forma parte de las perífrasis estudiadas. Como ya explicamos en la introducción, la literatura asume que ambos auxiliares incoativos tienden a expresar mayoritariamente actividades totalmente voluntarias, realizadas por un sujeto agentivo y con capacidad de decisión, pero rehúyen en cambio los infinitivos estáticos. Esto implicaría que son precisamente los infinitivos dinámicos, que expresan actividades o realizaciones (antes que estados), y de preferencia de aspecto durativo (no puntual), los que resultarían más apropiados para ocupar el lugar de [INF] de la construcción incoativa con ponerse o meterse.

principio expresar un evento durativo (p.ej. De joven, Ana tocó/tocaba la guitarra, Roasto 2013: 33). En términos de Slawomirski (1983: 100): "El error que más comúnmente se comete es la identificación de imperfectividad con duratividad, y, sobre todo, de perfectividad con puntualidad o terminatividad."

Además, incluso otros, como Rojo (1990: 33, 35), habían propuesto que los imperfectivos favorecen la interpretación atélica de un evento, al expresar "una situación (vista como) no terminada", mientras que los tiempos perfectivos favorecen la interpretación télica al expresar "una situación (vista como) terminada." Naturalmente, en nuestro caso estamos ante perífrasis incoativas que, de todos modos - sea cual fuere su aspecto - expresan el inicio de una acción (y no el final), por lo que resulta difícil aplicar rígidamente la noción de telicidad (y la de un término o punto final) a las construcciones aquí estudiadas. Por esa razón, se interpretarán los resultados del análisis a la luz de la definición unánimemente aceptada y más aplicable de ambos aspectos gramaticales, a saber, el enfoque o no en la estructura interna del evento. 
Sin embargo, las consideraciones sobre ponerse a y meterse a en la literatura se basan en ejemplos introspectivos. Resulta interesante, por tanto, verificar y medir empíricamente hasta qué punto los infinitivos de las dos perífrasis expresan dinamicidad. Con este objetivo, se han clasificado los infinitivos en cuatro categorías semánticas según el grado de transferencia de energía que expresan: alto (transitivos e inergativos) o bajo (inacusativos y copulativos). ${ }^{6}$ Recuérdese que los verbos inergativos son aquellos verbos intransitivos que se construyen con un sujeto-agente; las actividades o procesos que denotan (p.ej. reír, llorar, saltar, toser) dependen de la voluntad del agente. Los verbos inacusativos, por el contrario, se construyen con un sujeto paciente o tema (afectado o no afectado) que experimenta la acción; en general, denotan estados o eventos no agentivos (logros) y cubren dos clases semánticas verbales: los verbos de cambio (o ubicación) (p.ej. romper(se), abrir(se), hundir(se), secar(se), crecer, hervir, palidecer, florecer, caer, levantar(se), oscurecer) y los verbos de existencia y aparición (p.ej. aparecer, llegar, existir, ocurrir, venir, emerger) (Mendikoetxea 1999: 1579-1580).

Para la clasificación de los ejemplos, seguimos a Mendikoetxea (1999: 1577) quien señala que "la clasificación de un verbo como transitivo o intransitivo es algo intrínseco a su significado e independiente del uso concreto de ese verbo." Es decir, en todos los casos, los infinitivos se han analizado independientemente de su contexto semántico o de la semántica del sujeto (animado o no). Así, en el ejemplo (12), escribir se considerará como transitivo a pesar de la ausencia de un OD explícito, porque se sobreentiende que alguien escribe algo. Paralelamente, los verbos intrínsecamente intransitivos (morir, vivir, dormir) que aparecen con un OD externo o tautológico (13) se han clasificado como intransitivos, de acuerdo con su índole intransitiva inherente fuera del contexto.

(12) Trabajaría de nueve a siete, y llegaría a casa demasiado cansado como para ponerse a escribir. [CORPES XXI 10]

(13) Poco importa que Santa Teresa de Jesús declare en su autobiografía "que en cosa de la fe, contra la menor ceremonia de la Iglesia que alguien viese yo iba, por ella me pondría yo a morir mil muertes." [CORPES XXI 11]

Cabe subrayar que los verbos transitivos presentan el grado más elevado de dinamicidad, seguidos de los verbos inergativos, los inacusativos y, por último, los copulativos (Langacker 1991; Enghels 2007: 31, 45, 186). Así, los infinitivos [TR] e [INERG] se han considerado como dinámicos, pero los infinitivos [INAC] y los [COP], como no dinámicos.

6 Nótese que el criterio de la (in)transitividad de los infinitivos se trata aquí dentro del análisis semántico, pero está vinculado también a la sintaxis. Así, García-Miguel (2015: 294) incluye en la categoría de construcciones

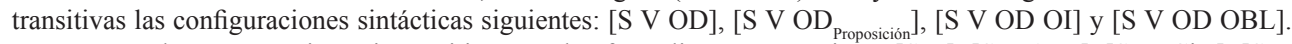
Por su parte, las construcciones intransitivas pueden formalizarse como sigue: [S V], [S V ATR], [S V: Cita], [S V OBL], [S V OI] [siglas adaptadas al español]. 
+ Dinámico

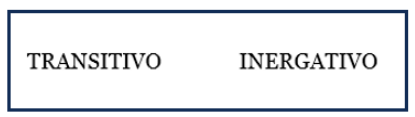

- Dinámico

INACUSATIVO COPULATIVO

\section{DINAMICIDAD}

Figura 1. Grado de dinamicidad de los infinitivos

Los resultados de las construcciones con ponerse y meterse se presentan en la Tabla 5. Los auxiliares se combinan mayoritariamente con infinitivos transitivos e inergativos (dinámicos), pero casi no se asocian con infinitivos no dinámicos (inacusativos y copulativos)

\begin{tabular}{|c|c|c|c|c|}
\hline \multirow{2}{*}{} & \multicolumn{2}{|c|}{ ponerse } & \multicolumn{2}{c|}{ meterse } \\
\cline { 2 - 5 } & $\#$ & $\mathbf{\%}$ & $\#$ & $\mathbf{\%}$ \\
\hline TR & 1477 & $\mathbf{5 0 , 5}$ & 528 & $\mathbf{7 3 , 2}$ \\
\hline INERG & 1388 & 47,5 & 166 & 23 \\
\hline INAC & 58 & 2 & 22 & 3,1 \\
\hline COP & 2 & 0,1 & 5 & 0,7 \\
\hline Total & $\mathbf{2 9 2 5}$ & $\mathbf{1 0 0}$ & $\mathbf{7 2 1}$ & $\mathbf{1 0 0}$ \\
\hline
\end{tabular}

$\mathrm{X}^{2}=244,18, \mathrm{df}=3, \mathrm{p}=2,200 \mathrm{e}-16$

Tabla 5. Dinamicidad del infinitivo

\subsubsection{Factores relacionados con la perifrasis completa}

\subsubsection{La negatividad asociada con la perífrasis}

Pasamos a los parámetros que tienen que ver con la perífrasis en su totalidad. En primer lugar, los ejemplos incoativos se han dividido en dos clases, según el matiz semántico que expresen: la categoría [neutro-positivo] y la categoría [negativo]. La diferencia entre el matiz positivo y el matiz neutro muchas veces es borrosa, y por eso se han agrupado en una clase. Los ejemplos neutros son los que no se asocian con una connotación particularmente positiva o negativa; su significado incoativo es neutro (14). Los ejemplos positivos, por su parte, tienen un infinitivo que expresa una acción positiva, cuya ejecución conllevará una consecuencia positiva para el agente o para las personas implicadas (15-16).

(14) Esta mañana, lo he visto otra vez. Un perro juguetón que, agobiado por el calor, se ha metido a chapotear en el estanque del parque. [Sketch engine $]^{7}$

$7 \quad$ Al discutir el ejemplo (14) con hablantes nativos, estos consideraban que no contenía una incoativa, porque meterse sería sinónimo de introducirse. Lo mismo vale para (16), donde meterse podría interpretarse como 'entrar en el campo para felicitar a los campeones' y (18), donde se entendería el verbo como 'introducirse en el portón'. Si bien admitimos que estos ejemplos presentan una persistencia del uso locativo de meter, como explicamos en 
(15) Para zanjar de una vez por todas la cuestión, hubo un momento en que Lorena se puso a dar brincos de felicidad por el jardín mientras en nombre de los dos gritaba: "i $\underline{\text { Somos }}$ felices! ¡Asquerosamente felices! Felices, felices, felices. [CORPES XXI 12]

(16) Si ganáis la Champions seré de los primeros en meterme a felicitaros, como felicitaría a un amigo culé. [Sketch engine]

En cambio, los ejemplos que se vinculan con una connotación negativa o peyorativa pertenecen a uno de los dos grupos siguientes. El primero de ellos está formado por los ejemplos incoativos cuyo infinitivo expresa inherentemente una acción negativa; este es el caso, por ejemplo de atacar, robar, desvalijar, denostar, matar, pillar, drogarse, pontificar, insultar, etc. Así, en las frases (17-18) se efectúa una acción negativa y el infinitivo de la incoativa se interpreta inherentemente como negativo.

(17) Me llamaron a las cuatro y media de la mañana. Una voz de hombre se puso a insultarme. [CORPES XXI 13]

(18) Eran alrededor de las 9:30 de la mañana que sucedió el hecho, los hombres aprovecharon que el portón estaba abierto para meterse a desvalijar la casa, para lo cual golpearon en la cabeza a la persona que se encarga del oficio de la casa. [Sketch engine]

El segundo grupo de casos negativos es más amplio y comprende los ejemplos cuyo infinitivo en sí es neutro fuera del contexto, pero cuya acción incoativa es percibida como negativa. Esto es el caso, por ejemplo, cuando el narrador (u otra persona de la historia) desprecia la acción y la interpreta como negativa (19-20): estudiar y crear en sí no son infinitivos negativos, pero en esta frase los personajes no consideran positiva la acción incoativa. En (21), usar es también un infinitivo neutro, pero el evento se percibe como negativo, porque es susceptible de desencadenar consecuencias negativas. Asimismo, es posible que resuene un tono de reproche, porque el sujeto empieza a entrometerse en algo o a ocuparse de un tema/una profesión/una actividad que no es de su incumbencia y fuera de su área de especialidad (22), o a hablar de algo sin tener los conocimientos necesarios (23) y/o sin fundamento (haciendo afirmaciones infundadas por falta de conocimiento o experiencia) (24).

(19) Juan no parecía del todo satisfecho con la idea de que su mujer se pusiera a estudiar filosofía. [CORPES XXI 14]

(20) Me parece una pérdida de tiempo meterse a crear una consola, el mercado no da para una cuarta consola (PS3, XBOX 360, Wii), estas ideas para mi q [sic] estan en fase de prueba. [Sketch engine]

(21) El peligro es que meterse a usar en este lenguaje SI atiza la xenofobia. [Sketch engine]

(22) [...] reafirmaba que la Iglesia nunca debía meterse a hacer política, aunque desde el Gobierno español seguramente piensen justo lo contrario. [Sketch engine]

\footnotetext{
las paginas 2-3, son ejemplos que se han incluido en el análisis como perífrasis, porque formalmente tienen la estructura 'meterse $+\mathrm{a}+$ infinitivo', incluso si están dentro de un contexto locativo, con un CLOC que precede o sigue (o que queda implícito). Solo se han descartado del análisis los ejemplos que tienen un CLOC intercalado entre Aux e INF (meterse en un lugar a hacer algo).
} 
(23) Tal y como yo veo todo esto, su error en este caso ha sido meterse a hablar de algo de

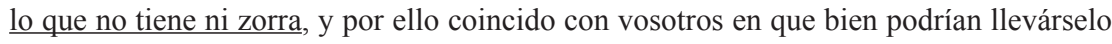
los demonios. [Sketch engine]

(24) El año 2009 sería un año ideal para que las religiones se quitaran las vendas de los ojos. Que dejaran de hacer el gilipoyas acojonando a la gente con que van a ir al infierno si se ponen condón o si son homosexuales y que usen su entramado social para ayudar a que el mundo sea un lugar mejor. Por qué coño se meterán a hablar de sexo y de familia, $\underline{\text { si los curas no tienen (oficialmente) ni lo uno ni lo otro. [Sketch engine] }}$

Los datos cuantitativos de la clasificación global entre [neutro-positivo] y [negativo] se presentan en la Tabla 6:

\begin{tabular}{|c|c|c|c|c|}
\hline \multirow{2}{*}{} & \multicolumn{2}{|c|}{ ponerse } & \multicolumn{2}{c|}{ meterse } \\
\cline { 2 - 5 } & $\#$ & $\mathbf{\%}$ & $\#$ & $\mathbf{\%}$ \\
\hline Neutro/+ & 2615 & $\mathbf{8 9 , 4}$ & 205 & 28,4 \\
\hline Negativo & 310 & 10,6 & 516 & $\mathbf{7 1 , 6}$ \\
\hline Total & $\mathbf{2 9 2 5}$ & $\mathbf{1 0 0}$ & $\mathbf{7 2 1}$ & $\mathbf{1 0 0}$ \\
\hline
\end{tabular}

Tabla 6. Negatividad del evento incoativo

De estos primeros resultados podemos deducir que las dos perífrasis parecen ser polos opuestos en cuanto al matiz que transmiten: ponerse expresa mayoritariamente acciones incoativas neutras (o positivas), mientras que meterse aporta claramente una connotación negativa en la mayoría de sus contextos de uso. Veremos más adelante si este efecto también se corrobora en el modelo de regresión logística y si, en el plano cualitativo, los dos verbos presentan también diferencias en cuanto a la distribución de los dos subgrupos negativos señalados más arriba.

Además, con el fin de minimizar los posibles fallos de nuestra clasificación, que se basa en buena medida en una interpretación subjetiva de la semántica del contexto, hemos recurrido a una segunda anotación para mejorar la fiabilidad del análisis (Glynn 2010; Zeschel 2010). Así, un hispanohablante nativo ha repetido el análisis, codificando de forma independiente un muestreo arbitrario de 200 ejemplos del mismo corpus. Esta persona no conocía el objetivo del análisis y se le pidió que clasificara las perífrasis incoativas con ponerse y meterse según el matiz que apreciaba: neutro/positivo o negativo. Posteriormente, se compararon los resultados con nuestro propio análisis y se calculó el grado de concordancia entre ambas codificaciones, para evaluar la precisión de los análisis. Se empleó para ello el test de kappa (Cohen 1960), que indica la fuerza de la concordancia y varía entre $\kappa=0$ (si no hay concordancia alguna) y $\kappa=1$ (si la concordancia es total). En general, un kappa de 0,7 o superior indica una coincidencia muy aceptable entre los codificadores (Enghels \& Jansegers 2013: 975). La concordancia entre los dos muestreos analizados, referidos a la clasificación de los ejemplos en términos de su negatividad, es bastante elevada $(\kappa=0,715){ }^{8}$

8 De acuerdo con Landis \& Koch (1977), la fuerza de la concordancia se interpreta como sigue: $<0,2$ (pobre); $>0,2 \leq 0,4$ (suficiente) $>0,4 \leq 0,6$ (media); $>0,6 \leq 0,8$ (considerable) $>0,8 \leq 1$ (muy buena). En cambio, según 
Así pues, con esta segunda anotación hemos podido reforzar nuestra clasificación y con ello, los resultados obtenidos.

\subsubsection{La negación asociada con la perífrasis}

Este parámetro semántico se relaciona estrechamente con el anterior. Es de suponer que un matiz peyorativo a menudo se asocia con la presencia de una partícula de negación en la frase, como se advierte en los ejemplos antriores (25) o (22). Sin embargo, hemos constatado que no siempre debe ser así, es decir, que un ejemplo de connotación peyorativa no siempre es una frase negativa (ver (26), o los ejemplos (23) y (24) más arriba) y viceversa, una frase negativa (construida con una partícula negativa como no, nunca, etc.) no siempre contiene una connotación peyorativa, sino que también puede ser neutra $(27 a-b)$.

(1) $[\ldots]$ pero no te metas a tratar de intermediar entre ellos, porque entonces aún puede salpicarte más la situación, y este es un tema que los dos tienen que saber solucionar. [Sketch engine]

(2) ¿Por qué se metería a husmear en donde nada se le había perdido? [CORPES XXI 15]

(3) a. Supongo que tiene algún tipo de explicación que cualquier psicólogo aficionado encontraría en dos patadas, pero nunca me he puesto a pensarlo. [CORPES XXI 16] b. Este chico vale para todo. Juega al fútbol, posa como nadie y ahora también diseña... $</ \mathrm{p}><\mathrm{p}>$ Siendo el marido de Victoria y un 'fashionista' empedernido, Beckham no podía estar mucho tiempo sin meterse a diseñar alguna que otra línea de ropa, ¿verdad? Y más si tenemos en cuenta que a las 'celebrities' les ha dado por crear modelitos a diestro y siniestro. $</ p><p>$ Pues bien, el guapísimo futbolista quiere crear una línea de trajes de alta costura para que todos los hombres tengan tanto gusto a la hora de vestir como él y, ¿sabes que quién ha sido la idea? Pues de su mujercita, Victoria, ¿de quién sino? [Sketch engine]

Por tanto, hemos analizado los ejemplos también en función de este criterio, para verificar si una perífrasis se asocia más con la negación que la otra. En los ejemplos negativos, la perífrasis incoativa se combina con una partícula de negación (como no, ni, jamás, nunca, sin, etc.) que incide sobre el auxiliar. Así, este parámetro cuenta dos regresores: [con_negación] y [sin_negación].

Observénse los resultados en la Tabla 7: ponerse aparece con abrumadora preferencia en frases afirmativas (no negativas), mientras que meterse se combina con frecuencia con una partícula de negación (obviamente mucho más que ponerse: el 65,2\% vs. el 2,9\%). Es posible que los resultados de este parámetro estén interrelacionados con los anteriores, es decir, con la negatividad expresada.

Fleiss (1981), la interpretación es la siguiente: $<0,40$ (pobre); $>0,40 \leq 0,75$ (de suficiente a buena); y $>0,75$ (excelente). 


\begin{tabular}{|c|c|c|c|c|}
\hline \multirow{2}{*}{} & \multicolumn{2}{|c|}{ ponerse } & \multicolumn{2}{c|}{ meterse } \\
\cline { 2 - 5 } & $\#$ & $\mathbf{\%}$ & $\#$ & $\mathbf{\%}$ \\
\hline Con_negación & 86 & 2,9 & 470 & $\mathbf{6 5 , 2}$ \\
\hline Sin_negación & 2839 & $\mathbf{9 7 , 1}$ & 251 & 34,8 \\
\hline Total & $\mathbf{2 9 2 5}$ & $\mathbf{1 0 0}$ & $\mathbf{7 2 1}$ & $\mathbf{1 0 0}$ \\
\hline
\end{tabular}

Tabla 7. Negación del evento incoativo

\subsubsection{Duración del evento incoativo}

El penúltimo parámetro semántico que se añade al modelo es la duración del evento incoativo. Los ejemplos (28a) y (28b) se refieren al ingreso en una carrera universitaria: la acción de empezar estudios superiores. Por el contrario, en ejemplos como (29), que expresan también la acción de 'ponerse a estudiar', se trata más bien de una actividad temporalmente delimitada que tiene lugar en un determinado momento (esa noche); por tanto, la incoativa en (29) no es durativa, no se prolonga en el tiempo.

(28) a. Paula.-(Fulminándola con la mirada.) Por eso me puse a estudiar, Amanda. Cuando me casé con tu padre ya era licenciada en Filología. Ya escribía. [CORPES XXI 17] b. Bardem terminó COU con esfuerzo y se metió a estudiar Artes y Oficios porque lo que quería era ser pintor, después trabajó como portero de discoteca y bailarín de streaptease. [CORPES XXI 18]

(29) "Podría haberlo hecho perfectamente", dice su padre. Escondía los libros debajo de la cama y, a media noche, encendía la luz de su dormitorio y se ponía a estudiar con un nudo en el estómago que a menudo la hacía correr hasta el baño. [CORPES XXI 19]

Así pues, se han clasificado los ejemplos en dos categorías, de acuerdo con la duración del evento incoativo. Los dos regresores se denominan [actividad_delimitada] y [actividad_prolongada]. Los resultados obtenidos son los siguientes:

\begin{tabular}{|l|l|l|l|l|}
\hline & \multicolumn{2}{|l|}{ ponerse } & \multicolumn{2}{l|}{ meterse } \\
\cline { 2 - 5 } & $\#$ & $\mathbf{\%}$ & $\#$ & $\mathbf{\%}$ \\
\hline actividad_delimitada & 2778 & $\mathbf{9 5}$ & 666 & $\mathbf{9 2 , 4}$ \\
\hline actividad_prolongada & 147 & 5 & 55 & 7,6 \\
\hline Total & $\mathbf{2 9 2 5}$ & $\mathbf{1 0 0}$ & $\mathbf{7 2 1}$ & $\mathbf{1 0 0}$ \\
\hline
\end{tabular}

$\mathrm{X}_{2}=7,49, \mathrm{df}=1, \mathrm{p}=0,006$

Tabla 8. Duración del evento incoativo 
A primera vista, ponerse y meterse no se diferencian mucho en cuanto a este parámetro. Los ejemplos de actividad prolongada, que expresan un cambio profundo y durativo en la vida de alguien, resultan más bien escasos. Ambas perífrasis se emplean en general para expresar acciones incoativas delimitadas, antes que prolongadas.

\subsubsection{Género textual}

En último lugar, resulta interesante detectar si existe una correlación entre el uso de las perífrasis con ponerse/meterse y el género discursivo. De esta manera, los ejemplos incoativos del corpus se han etiquetado en función del contexto discursivo en el que aparecen: la narración (30), el diálogo (31) o el estilo indirecto (32).

(30) En momento posterior ya se metió a fondo a desgranar su política de austeridad. [CORPES XXI 20]

(31) Doña Perfecta.- Lo único que voy a negarte es la intención que me has atribuido. ¿Con qué derecho te metes tú a juzgar lo que sólo conoces por conjeturas? ¿Eres Dios para conocer las intenciones? [CORPES XXI 21]

(32) La dirigente popular, en declaraciones a los periodistas en la sede nacional del PP, exigió al PSOE que actúe con "responsabilidad" y solicitó a los socialistas y al resto de formaciones en Navarra que se pongan a trabajar a fin de "ser útiles" para los ciudadanos de esta autonomía. [CORPES XXI 22]

Sin embargo, como se puede ver abajo, en la Tabla 9, las perífrasis incoativas en el estilo indirecto son tan infrecuentes que por motivos prácticos las agrupamos en la categoría de los diálogos. Por tanto, el parámetro se añade al modelo con dos regresores diferentes: [narración] y [diálogo], incluyendo en esta última clase tanto los diálogos propiamente dichos (indicados por medio de comillas o guiones) como el estilo indirecto (introducido por que).

Por lo demás, se puede apreciar una marcada diferencia entre ponerse y meterse: en el corpus, meterse aparece con más frecuencia en diálogos, mientras que la distribución de ponerse entre narración y diálogos parece más equilibrada.

\begin{tabular}{|c|c|c|c|c|}
\hline \multirow{2}{*}{} & \multicolumn{2}{|c|}{ ponerse } & \multicolumn{2}{c|}{ meterse } \\
\cline { 2 - 5 } & $\#$ & $\mathbf{\%}$ & $\#$ & $\mathbf{\%}$ \\
\hline diálogo & 1345 & 46 & 505 & $\mathbf{7 0}$ \\
\hline narración & 1577 & 53,9 & 211 & 29,3 \\
\hline estilo indirecto & 3 & 0,1 & 5 & 0,7 \\
\hline Total & $\mathbf{2 9 2 5}$ & $\mathbf{1 0 0}$ & $\mathbf{7 2 1}$ & $\mathbf{1 0 0}$ \\
\hline
\end{tabular}

$$
\mathrm{X}_{2}=147, \mathrm{df}=2, \mathrm{p}=0,000
$$

Tabla 9. Género discursivo de la incoativa 


\subsubsection{Tabla de recapitulación}

En suma, la descripción de todos los parámetros expuestos hasta aquí nos lleva a la siguiente tabla de recapitulación de las nueve variables incluidas en el modelo.

\begin{tabular}{lllllll}
\hline No & Variable & Índole & & & Etiquetaje de los regresores \\
\hline 1 & Asociación & Categórica & c/ & 2 & niveles & 1_INF, múltiples_INF \\
\hline 2 & Animacidad_SN ${ }_{1}$ & Categórica & c/ & 3 & niveles & animado, inanimado, impersonal \\
\hline 3 & Aspecto_verbal & Categórica & c/ & 2 & niveles & imperfectivo, perfectivo \\
\hline 4 & Dinamicidad_INF & Categórica & c/ & 4 & niveles & TR, INERG, INAC, COP \\
\hline 5 & Negatividad & Categórica & c/ & 2 & niveles & +/neutro, - \\
\hline 6 & Negación & Categórica & c/ & 2 & niveles & con negación, sin_negación \\
\hline 7 & Duración & Categórica & c/ & 2 & niveles & delimitada, prolongada \\
\hline 8 & Género_textual & Categórica & c/ & 2 & niveles & diálogo, narración \\
\hline
\end{tabular}

Tabla 10. Síntesis de las variables predictoras morfosintácticas y semánticas y sus niveles

\section{RESULTADOS Y DISCUSIÓN}

Se ha ejecutado un análisis de RL, modelando la elección verbal en función de las ocho variables predictoras implicadas. En el modelo construido, meterse funciona como el "nivel de éxito" en el modelo (o success outcome) y ponerse, como el "nivel de referencia" (o reference level). ${ }^{9}$ Con vistas a obtener la mejor modelación estadística, construimos varios modelos previos y eliminamos en cada etapa los predictores que no contribuyen significativamente al efecto global en la variable respuesta. ${ }^{10}$ De este modo, se eliminaron del modelo los predictores Animacidad_SN, Dinamicidad_INF y Duración: la diferencia entre las dos perífrasis no se encuentra en el tipo de sujeto (animado) o de infinitivo (dinámico) o en la duración (temporalmente delimitada) del evento incoativo.

Esto significa que se han conservado en el modelo definitivo cinco predictores estadísticamente significantes $(\mathrm{p}<0,05)$ y con buenos indicios AIC (Akaike's Information Criteria): Asociación, Negatividad, Negación, Aspecto_verbal y Género_textual. Además, el modelo revela también dos interacciones, que se discutirán más adelante. La Tabla 11 resume las estadísticas que permiten evaluar la calidad global del modelo.

\begin{tabular}{|c|c|}
\hline Número de observaciones & 3646 \\
\hline Null deviance & $5680,9$ (on $4439 \mathrm{df})$ \\
\hline Residual deviance & 3822,4 (on 4426 df) \\
\hline Likelihood Ratio test statistic & 1858,50 \\
\hline AIC & 3850,4 \\
\hline
\end{tabular}

9 Esta ha sido una elección arbitraria. También habríamos podido escoger ponerse como "nivel de éxito". 10 Para más información sobre este procedimiento, llamado backward stepwise regression, véase por ejemplo Burnham \& Anderson 2002. 


\begin{tabular}{|c|c|}
\hline $\mathrm{p}$-value (chi squared) & $\mathrm{p}<0,0001$ \\
\hline $\mathrm{C}$ & 0,834 \\
\hline $\mathrm{D}_{\mathrm{xy}}$ & 0,669 \\
\hline
\end{tabular}

Tabla 11. Resumen de estadísticas del modelo de RL

Los datos de la Tabla 11 muestran que el modelo de regresión logística es fiable y que predice bien la preferencia por uno de los dos verbos. Primero, la desviación - o la variación no explicada - del modelo con cinco predictores (residual deviance) es menor que la de un modelo con un solo intercepto, sin predictores (null deviance). Segundo, el valor del Likelihood Ratio test statistic corresponde a un valor elevado de 1858,5 , lo que indica a su vez que el modelo construido es mejor que un modelo sin predictor alguno. Además, el valor $p$ que lo acompaña es mucho más bajo que el umbral aceptado de 0,05 ( $\mathrm{p}<0,0001)$. Por tanto, el modelo final es muy significante. Por otro lado, el índice de concordancia $\mathrm{C}$ tiene un valor elevado, de 0,834 ; de acuerdo con la escala propuesta por Hosmer \& Lemeshow (2000: 162), un C cuyo valor está entre 0,8 y 0,9 es indicio de un modelo estadístico excelente (excelent). Por su parte, el Dxy de 0,669 es aceptable porque supera el límite mínimo de 0,6 , aunque no holgadamente.

Por último, la tabla de clasificación presentada abajo revela que el modelo construido predice correctamente el $90,5 \%$ de los datos en (comparado con solo un $66,2 \%$ en un modelo con un único intercepto). Además, la elección por ponerse se predice correctamente con mayor exactitud que la por meterse $(94,8 \%$ vs. $72,7 \%)$, probablemente porque disponemos de más casos analizados con ponerse. ${ }^{11}$

\begin{tabular}{llll}
\hline & Predicho & & \\
\cline { 2 - 4 } Observado & Ponerse & Meterse & Correcto (\%) \\
\hline Ponerse & 2775 & 150 & 94,8 \\
Meterse & 197 & 524 & 72,7 \\
Total correcto & & & 90,5 \\
\hline
\end{tabular}

Tabla 12. Tabla de clasificación para el modelo construido

Así pues, pese a que algunos parámetros analizados hayan sido descartados y se ignoren, el modelo final resulta ser un modelo fiable y fuerte en términos de calidad y potencial de predicción. Además, los valores VIF (Variation Inflation Factors) no señalan ningún riesgo potencial de multicolinearidad, al presentar todos ellos un valor inferior a 2,5 (esto es, inferior al umbral admitido de 4). Por consiguiente, podemos pasar a la descripción y discusión de los resultados del modelo, que se encuentran resumidos en la Tabla 13.

11 Los porcentajes se han calculado a partir de las cifras absolutas que nos ofrece R. Así, por ejemplo, del total de 2925 casos con ponerse, R indica que en 2775 la predicción se realizará correctamente. Así, el 94,8\% es el resultado del cálculo $(2775 / 2925) * 100$. El porcentaje $90,5 \%$ (total correcto) se obtiene a partir de la suma de los casos predichos correctamente de cada verbo $(2775+524)$, dividida por el total $(2775+150+197+524)$ y luego multiplicada por 100 . 


\begin{tabular}{lrrrrr}
\hline & $\begin{array}{r}\text { Coeficiente } \\
\text { estimado }\end{array}$ & $\mathbf{9 5 \%}$ IC & SE & $\mathbf{Z}$ & $\mathbf{p}$ \\
\hline (Intercepto) & $-0,99$ & $-1,11 /-0,87$ & 0,06 & $-15,97$ & $<0,0001$ \\
\hline $\begin{array}{l}\text { Asociación: múltiples_INF } \\
\text { (Ref. level: 1_INF) }\end{array}$ & 0,67 & $0,32 / 1,00$ & 0,17 & 3,80 & $<0,0001$ \\
\hline Negatividad: negativo & 2,13 & $1,96 / 2,29$ & 0,08 & 25,31 & $<0,0001$ \\
(Ref. level: neutro/positivo) & & & & & \\
\hline $\begin{array}{l}\text { Negación: negación } \\
\text { (Ref. level: sin_negación) }\end{array}$ & 1,70 & $1,42 / 1,99$ & 0,15 & 11,61 & $<0,0001$ \\
\hline $\begin{array}{l}\text { Aspecto_verbal: perfectivo } \\
\text { (Ref. level: imperfectivo) }\end{array}$ & $-0,69$ & $-0,84 /-0,53$ & 0,08 & $-8,61$ & $<0,0001$ \\
Género_textual: narración & & & & & \\
(Ref. level: diálogo) & $-0,58$ & $-0,74 /-0,43$ & 0,08 & $-7,43$ & $<0,0001$ \\
\hline
\end{tabular}

Tabla 13. Modelo de regresión logística con los coeficientes estimados para el nivel de éxito meterse, así como los standard errors (SE), los 95\% intervalos de confidencia (IC) de los coeficientes, Wald test statistic (z) y la probabilidad p.

Los coeficientes estimados y los gráficos tienen que interpretarse en función del nivel de éxito meterse: un coeficiente positivo indicará que la variable tiene un efecto positivo sobre la aparición de meter en un contexto dado, es decir, que aumenta la probabilidad de que encontremos el verbo meter si esa variable predictora está presente. Por el contrario, un coeficiente negativo indicará lo contrario: disminuye la probabilidad de encontrar meter. ${ }^{12}$ Cuanto más se aleja de cero el coeficiente (en sentido positivo o negativo), más fuerte será el efecto (Glynn 2010: 260). En este sentido, los coeficientes elevados (en términos absolutos), que tienen un efecto estadísticamente significante, indican una influencia fuerte sobre la probabilidad de encontrar uno de los dos verbos, mientras que los coeficientes cercanos a cero indican una influencia más débil.

\subsection{Asociación}

El grado de asociación es el primer parámetro que parece distinguir ambas perífrasis incoativas. Así, cuando dos o más infinitivos se encadenan y se asocian con el mismo auxiliar, aumenta la probabilidad de encontrar meterse. El coeficiente estimado es $0,67 \mathrm{y}$ el efecto es muy significante $(\mathrm{p}<0,0001)$. Se visualiza en la Figura 2:

12 "A negative regression coefficient means that predictor decreases the probability of that outcome" (Divjak 2010: 320). 


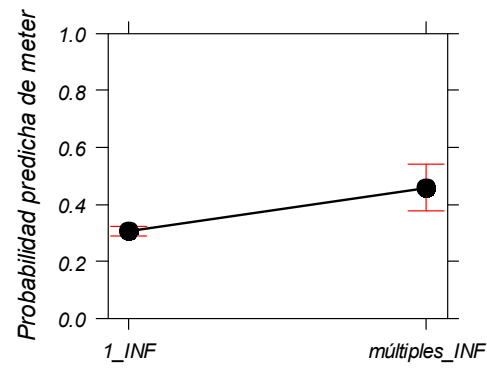

Figura 2. Grado de asociación en el modelo de RL

Los casos de baja asociación - con dos o más infinitivos regidos por un mismo auxiliar, sin que este auxiliar se repita ante cada infinitivo - se combinan más frecuentemente con meterse que con ponerse (33). Por el contrario, la múltiple rección es menos frecuente con ponerse, que entra más fácilmente en predicados complejos con un solo infinitivo (34) de modo que ponerse parece tener un grado (algo) más elevado de asociación que meterse y, en consecuencia, parece ser el verbo más gramaticalizado de los dos respecto a este parámetro.

(33) Debía de importar más de conseguir que la gente tenga más trabajo y haya menos paro así muchos no tendrían que meterse a cultivar plantas o a delinquir porque podrían llevar su vida honradamente. [Sketch engine]

(34) CHARLES. Joder, yo también me he puesto nervioso... ¡Todos nos hemos puesto a temblar en cuanto hemos visto aparecer al señor Kowalski en el comedor! [CORPES XXI 23]

\subsection{Negatividad asociada con la perífrasis}

El segundo parámetro que tiene una influencia en la elección entre las dos perífrasis es la negatividad. Se trata del predictor más fuerte del modelo, con un coeficiente estimado de 2,13. El efecto se visualiza en la Figura 3: una connotación negativa asociada con la perífrasis aumenta considerablemente la probabilidad de encontrar meterse.

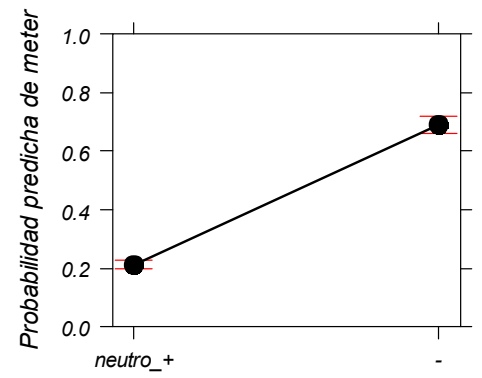

Figura 3. Negatividad en el modelo de RL 
Así pues, la negatividad parece muy característica de la perífrasis con meterse (35). Por el contrario, las incoaciones neutras y/o positivas son preferentemente expresadas por ponerse, como muestra (36).

(35) Por otro lado, vale, no sois jueces, pero entonces no deberíais meteros a criticar el trabajo de un Juez, porque probablemente ha estudiado la materia y vuestra única visión es un artículo de un periódico escrito por alguien que tampoco sabe Derecho. [Sketch engine]

(36) $[\ldots]$ de repente se puso a sonreír y a querer rescatar el cono menos derretido de su helado, que ya dejaba ríos de coco en las baldosas. [CORPES XXI 24]

Volvamos ahora a los dos grupos diferenciados dentro de la categoría [negativo], a saber, (i) el grupo de ejemplos con un infinitivo inherentemente negativo y (ii) el grupo de ejemplos cuya incoación es percibida como negativa. Si miramos más en detalle el conjunto de los distintos ejemplos negativos en función de estas dos categorías, se hace patente otra diferencia notable entre las dos construcciones:

\begin{tabular}{|c|c|c|c|c|}
\hline \multirow{2}{*}{} & \multicolumn{2}{|c|}{ ponerse } & \multicolumn{2}{c|}{ meterse } \\
\cline { 2 - 5 } & $\#$ & $\mathbf{\%}$ & $\#$ & $\mathbf{\%}$ \\
\hline Infinitivo negativo & 296 & $\mathbf{9 5 , 5}$ & 176 & 34,1 \\
\hline Percepción negativa & 14 & 4,5 & 340 & $\mathbf{6 5 , 9}$ \\
\hline Total & $\mathbf{3 1 0}$ & $\mathbf{1 0 0}$ & $\mathbf{5 1 6}$ & $\mathbf{1 0 0}$ \\
\hline
\end{tabular}

$$
\mathrm{X}_{2}=298, \mathrm{df}=1, \mathrm{p}=0,000
$$

Tabla 14. Clasificación de los ejemplos negativos de ponerse y meterse

Es decir, cuando la perífrasis con ponerse expresa una connotación negativa, resulta que en casi la totalidad de los casos (el 95,5\%), el infinitivo es inherentemente negativo (acciones como reñir, chismorrear, sollozar, cavilar, etc. 37a-b). Dicho de otro modo: [ponerse + infinitivo] casi nunca expresa una acción incoativa que se perciba como negativa por el hablante u otro participante del diálogo, pero cuyo infinitivo sea neutro fuera de ese contexto (solo un 4,5\% del corpus con ponerse) (38a-b):

(37) a. Ahora nos ponemos a reñir, pero enseguida nos reconciliamos. [CORPES XXI 25] b. - ¿Nos vamos a poner a chismorrear? [CORPES XXI 26]

(38) a. ¿Porque a usted por qué se pone a hacer una cosa que no sabe? [CORPES XXI 27] b. "Si no sabe qué es lo que se supone que su programa ha de hacer, es mejor que no se ponga a escribirlo." [CORPES XXI 28]

Con meterse, en cambio, la segunda categoría de ejemplos asociados con una percepción negativa está mucho más representada (el 65,9\%). Cada uno de los subtipos mencionados destacan con este verbo: o bien la acción iniciada se percibe como negativa, porque del contexto se infiere claramente que el narrador u otra persona de la historia la desprecia por 
una razón u otra (39a), o bien la percibe como negativa, porque es susceptible de acarrear consecuencias negativas para él u otros participantes implicados (39b). En otros casos, la percepción negativa es innegable, porque el agente empieza a efectuar una acción sin tener los conocimientos necesarios o requeridos para realizarla (39c). A veces, además, hay alguien que no sabe de lo que pretende hablar y lo hace sin fundamento (39d) o se ocupa de una profesión o una actividad que no es de su incumbencia (i.e. que está fuera de su área de especialidad) y esta intromisión se percibe como muy negativa (39e). ${ }^{13}$ Finalmente, [meterse + infinitivo] se emplea también para desaconsejar algo a alguien o disuadirle de una acción; en estos casos, resalta una vez más la percepción negativa del hablante sobre la acción (39f-g).

(39) a. De todos modos, tengo amigos, grandes cinéfilos a los que respeto, que prefieren que les saquen una muela que meterse a ver una de Rohmer. [Sketch engine]

b. La verdad es que el estrés que supone, sin apenas acabar la temporada, meterse a pensar donde se estará dentro de unos meses. [Sketch engine]

c. Y lo que siempre he dicho: Zapatero a tus zapatos, si no sabes de salud no te metas a asegurar la salud de la gente. [Sketch engine]

d. Judiator: pues no lo compres, ¿porqué [sic] critican el Iphone los que no lo tienen? Es algo que jamás he comprendido. Yo tengo un Iphone con muchísimas ventajas y algún defecto criticable... pero jamás me meteré a criticar algo que no utilizo o que tajantemente digo que no voy a utilizar. Es como cuando de pequeño te niegas a comer algo porque 'no te gusta' y tu madre te dice: "¿pero lo has probado?" [Sketch engine]

e. En ese caso el ayuntamiento no debería haberse metido a ser patrón museístico, para eso está el estado. [Sketch engine]

f. [...] "si buscas seguridad y comodidad personal, mejor no te metas a emprender, porque las iniciativas empresariales implican no dormir bastantes noches". [CORPES XXI 29]

g. Si odias el agua no te metas a nadar. Simple. [Sketch engine]

En la mayoría de estos ejemplos, además, el infinitivo en sí no es realmente negativo fuera del contexto en que aparece (ver, pensar, asegurar, nadar, emprender, etc.). Son infinitivos neutros, pero aparecen en un contexto que se percibe como negativo por el hablante $\mathrm{u}$ otro participante.

En suma, los resultados empíricos demuestran un contraste importante en el comportamiento de ponerse y meterse para este parámetro, no solo en el matiz subjetivo asociado (negativo vs. neutro), sino también en el tipo de negación expresado.

\subsection{Negación asociada con la perífrasis}

El tercer parámetro que el modelo de regresión logística mostró como parámetro válido es la presencia de una partícula de negación. Es decir, la probabilidad de meterse no solo au-

13 Está claro que criticar en (39d) es un infinitivo inherentemente negativo, por lo que el ejemplo también se podría haber clasificado en el primer grupo. No obstante, como se añade claramente un matiz de 'falta de conocimiento', el hablante percibe la actividad negativamente y por ello lo clasificamos mejor en el segundo grupo, junto con los ejemplos de (39); en nuestra opinión, predomina la idea de 'entrometerse' en algo que no es de su incumbencia y sin permiso, por lo que nos parece más próximo al segundo grupo. El tono de reproche que se advierte por parte del hablante (es decir, su percepción negativa) se impone sobre la negatividad del infinitivo en estos casos. 
menta significativamente cuando se añade una connotación peyorativa, sino también cuando se añade una negación a la frase. El efecto de esta variable es de 1,67 y, como muestra la Figura 4, destaca como el tercer parámetro que distingue ambas perífrasis.

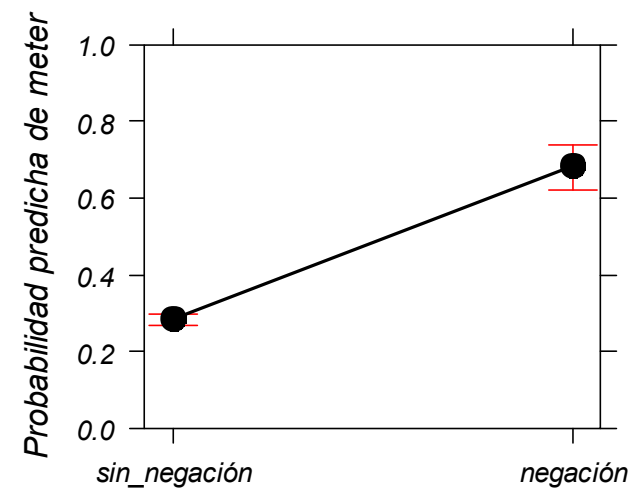

Figura 4. Negación en el modelo de RL

Así pues, meterse tiende a aparecer más en oraciones negativas (40), mientras que, por el contrario, ponerse aparece con más frecuencia en contextos afirmativos (41).

(40) Lo primero: Mejor en una escuela de cine que apaleando perros. No sé si me entendéis. Si no tenéis otra cosa en mente, ¿por qué no probar si de verdad os gusta? No me meteré a recomendar escuelas. Cada uno ya sabrá el tiempo y dinero del que dispone, y cuáles son sus prioridades. [Sketch engine]

(41) Me puse a llorar desconsolada mientras subía con vosotros y tres o cuatro amigos más por las Ramblas, hacia la plaza de Cataluña. [CORPES XXI 30]

\subsection{Aspecto gramatical}

La cuarta variable que distingue las dos perífrasis es el aspecto gramatical. La Figura 5 muestra que un tiempo imperfectivo tiende a aumentar la probabilidad de la aparición de una perífrasis con meterse más que con ponerse. Se trata, por ejemplo, del presente de indicativo o el presente de subjuntivo (42). Con ponerse, se observa lo contrario: se conjuga con más frecuencia en tiempos verbales perfectivos, como el pretérito perfecto simple o el pluscuamperfecto (43).

(42) - No quiero comprender nada. Si me meto a comprender me hago hermanita de la caridad o me voy de misionera a la India. [CORPES XXI 31]

(43) Los años se pusieron a pasar más y más rápido. [CORPES XXI 32] 


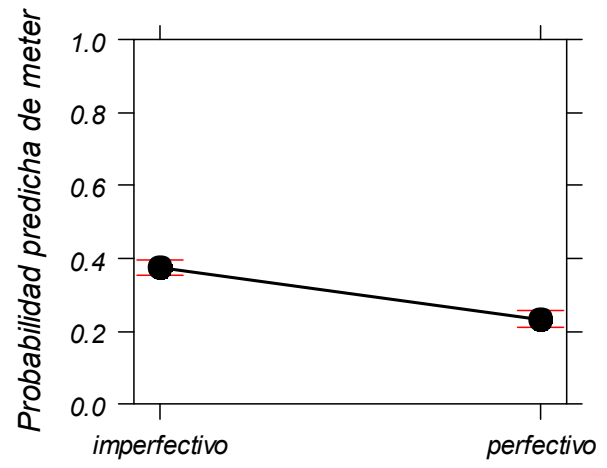

Figura 5. Aspecto gramatical en el modelo de RL

Así pues, dentro del lapso de tiempo en el que tiene lugar el evento incoativo, la perífrasis con ponerse tiende a interpretarse como un todo (sin fases intermedias distinguibles) cuando ocurre en un tiempo perfectivo. Por el contrario, la incoativa expresada con meterse atiende más a la estructura interna del evento. Aun así, el efecto es algo menos fuerte que el de la negatividad y la negación.

\subsection{Género textual}

Finalmente, el último parámetro que se ha tenido en cuenta en el modelo es el género textual en el que se inscribe la perífrasis. En diálogos, esta tiende a construirse más fácilmente con meterse, mientras que en la narración parece predominar ponerse.

(44) -¡Ah, qué horror! -exclamó mi madre-. ¿Quién se mete ahora a separar a esas dos furias? ¿Por qué no lo hacen ya? [CORPES XXI 33]

(45) Calló y se puso a comer su ensaladilla con pausada delectación y exquisitos modos. [CORPES XXI 34]

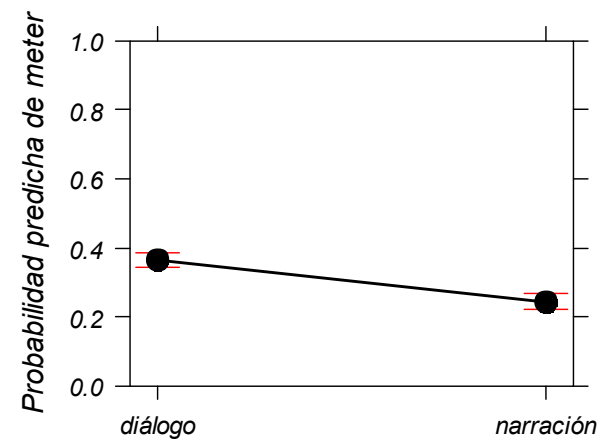

Figura 6. Género textual en el modelo de RL 


\subsection{Interacción género textual * aspecto verbal}

Por otro lado, además del efecto significante individual de los parámetros anteriores, se encuentran en $\mathrm{R}$ dos interacciones entre algunas de estas variables. En primer lugar, parecen interactuar el género discursivo (diálogo vs. narración) y el aspecto gramatical. Meterse aparece más que ponerse en tiempos verbales imperfectivos, y es sobre todo en los diálogos donde es más evidente este efecto.

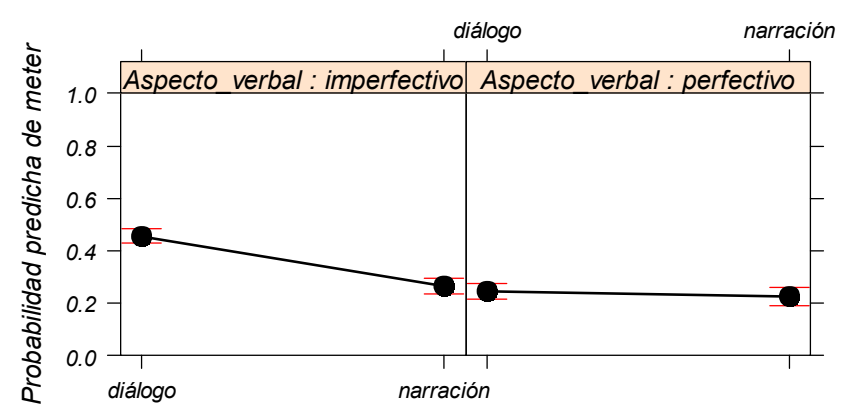

Figura 7. Género textual * Aspecto gramatical en el modelo de RL

Aun así, la presencia de esta interacción en el modelo tampoco está injustificada, ya que es precisamente en los diálogos donde son más abundantes los tiempos imperfectivos (como el presente de indicativo o de subjuntivo) (46).

(46) "si eres concejal de obras, y lo que sabes de verdad es burocracia del empleo, si te metes a elegir cosas para la cual no estas capacitado...das estos resultado,...vamos a ser inteligentes...y zapatero a tus zapatos, sino asesórate o........ [Sketch engine]

\subsection{Interacción negatividad * negación}

En segundo lugar, también parecen entrar en interacción la expresión de un matiz negativo con meterse y la presencia de una partícula de negación en la frase.

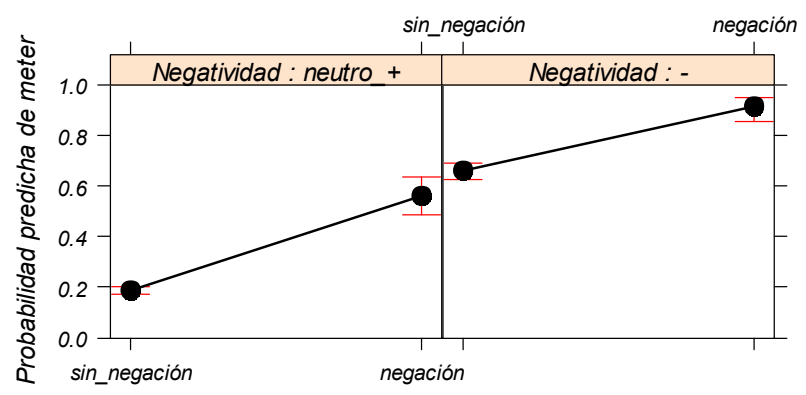


Figura 8. Negatividad * Negación en el modelo de RL

Así, de la Figura 8 se deduce que meterse aparece preferentemente en contextos de negación (esto es, contextos no afirmativos). Además, si se añade a la perífrasis el matiz peyorativo, la probabilidad de encontrar meterse aumenta aún más. Esta interacción no debe sorprender, pues los contextos de negatividad implican a menudo consejos negativos (47):

(47) Yo jamás me metería a ver una película (¡de casi tres horas!) con esos veinte minutos de presentación, por las razones expuestas. [Sketch engine]

\section{CONCLUSIÓN Y DISCUSIÓN FINAL}

En conclusión, la regresión logística aplicada a los ejemplos incoativos 'prototípicos' (esto es, sin CLOC intercalado entre el auxiliar y el infinitivo) nos ha permitido detectar y corroborar algunas diferencias entre las perífrasis con ponerse y meterse. Meterse resulta estar menos gramaticalizado que ponerse, al presentar un grado más bajo de asociación y regir más frecuentemente varios infinitivos a la vez, sin repetición del auxiliar. Meterse destaca también como el verbo semánticamente más especializado y marcado de los dos cuasisinónimos. Se decanta por los contextos semánticamente negativos o percibidos como tales, mientras que ponerse aparece más en contextos más neutros (o positivos). Esta distinción (negativo vs. neutro) motiva el uso de los dos verbos en los ejemplos (3a-c), expuestos en la Introducción (cf. supra).

Asimismo, el evento incoativo expresado con meterse se asocia muchas veces con una partícula de negación, reforzando el tono de reproche hacia la intromisión del agente en algo o su falta de competencia. Aparece también con mucha mayor frecuencia que ponerse en diálogos y, por otro lado, suele conjugarse en un tiempo verbal imperfectivo. En el plano semántico, sin embargo, los verbos no difieren en el tipo de sujeto-agente que inicia la acción (animado), en el tipo de infinitivo (dinámico) o en el tipo de evento incoativo (más bien delimitado).

Así pues, la diferencia principal en el uso de las dos perífrasis reside en el contexto y en el matiz que transmiten. Cabe añadir que la negatividad atestiguada con meterse parece encontrarse también en usos no perifrásticos del verbo (pseudo-copulativos (48) o locativos (49), por ejemplo), es decir, que probablemente la negatividad se asocia más con el lexema de meter en general. Esto confirmaría los planteamientos de otros autores como Grijelmo (2000: 75), quien lo define como "un verbo vulgar, negativo en todos sus contextos de uso".

(48) -Un cabrón con pintas -corroboraba Ricart. Este tipo perdió el contacto con la llamada clase obrera hace veinte años. No sabe lo que cuesta el pan, o el vodka, o la leche, o el autobús. Y ahora se ha metido a economista. [CORPES XXI 35]

(49) Nada más empezar, Martín Goyeneche, director clínico, entró a degüello contra Lluvia. ¿Quién era ella para meterse en cómo trabajaba su personal? ¿Qué autoridad científica tenían los jinetes para decir a sus veterinarios cómo debían proceder? [CORPES XXI 36]

Además, el estudio detallado de las incoativas con meterse nos permite de hecho clasificarlas en cuatro categorías. Así, meterse se utiliza en cuatro contextos de uso principales, la mayoría de los cuales no son usos característicos de ponerse: (i) un uso perifrástico que 
encierra una connotación negativa (50), (ii) un uso perifrástico donde la unidad [Aux - $(\mathrm{a}+$ INF)] sigue o precede a un complemento locativo (ya sea expreso (51a-c) o tácito (51d)), ${ }^{14}$ (iii) una combinación del contexto negativo y locativo (52), y, por último, (iv) un reducido grupo de auténticos contextos incoativos que carecen de matiz negativo y de locativo (53-54). Ponerse, por el contrario, expresa mayoritariamente eventos incoativos puros (y neutros) (55).

\begin{tabular}{|c|c|c|c|c|}
\hline \multirow{2}{*}{} & \multicolumn{2}{|c|}{ ponerse } & \multicolumn{2}{c|}{ meterse } \\
\cline { 2 - 5 } & $\#$ & $\mathbf{\%}$ & $\#$ & $\mathbf{\%}$ \\
\hline Contexto negativo & 295 & 10,1 & 494 & $\mathbf{6 8 , 5}$ \\
\hline Contexto locativo & 8 & 0,3 & 111 & 15,4 \\
\hline Contexto negativo + locativo & 15 & 0,5 & 22 & 3,1 \\
\hline Contexto incoativo auténtico & 2607 & $\mathbf{8 9 , 1}$ & 94 & 13 \\
\hline Total & $\mathbf{2 9 2 5}$ & $\mathbf{1 0 0}$ & $\mathbf{7 2 1}$ & $\mathbf{1 0 0}$ \\
\hline & $\mathrm{X}_{2}=18,0, \mathrm{df}=3, \mathrm{p}=0,000$ \\
\hline
\end{tabular}

Tabla 15. Contextos de uso del incoativo de ponerse y meterse

(50) La comida es muy barata en general, entre 4 y 6 euros puedes comer bien, el agua es gratis, pan no hay, cafe tampoco. Esto reduce mucho los gastos del viaje. Si no te metes a comer sushi, que es más caro y no se encuentra con facilidad, puedes hacer las comidas del día con 20 euros. [Sketch engine]

(51) a. Mucho cuidado donde os metéis a desayunar en Burguete. [Sketch engine]

b. Pues la verdad es que ni idea, miramos algún sitio y nos metemos a comer. [Sketch engine]

c. La vivienda tiene 3 dormitorios, salón, cocina, lavadero, baño, aire acondicionado, ascensor, amueblado, cocina equipada. En perfecto estado para meterse a vivir. [Sketch engine]

d. $\quad><\mathrm{p}>$ Macoy le ha dicho a Malena que no tenga miedo a meterse a nadar que con esas tetas no se ahoga fácil. [Sketch engine]

(52) $[\ldots]$ yo personalmente no me metería a trabajar ahí:S. [Sketch engine]

(53) a. Ella se metió a trabajar en cuanto salió de la escuela y ha cosido desde gorros de quirófano hasta blusas de señora, así que no se le caen los anillos. [Sketch engine]

b. El sonido de ese idioma romántico despierta en muchas personas sueños y añoranzas inesperados y por eso muchos se meten a estudiar el italiano. [Sketch engine]

(54) a. Deberías meterte a entrenar, con tu sabiduría no saldría mal nunca. [Sketch engine] b. No me he metido a investigar mucho en la cocina pero puedo sobrevivir perfectamente. [Sketch engine]

(55) Dos albañiles, Juan y Rufino, sentados, sacan unas tarteras y se ponen a comer. [CORPES XXI 37]

14 Subrayamos que no se trata aquí de los ejemplos incoativos que tienen un CLOC intercalado entre Aux y INF (ejemplos que se han descartado del presente análisis), sino que nos referimos a los ejemplos incoativos con la estructura $[$ Aux $-(\mathrm{a}+\mathrm{INF})]$ pero insertados en un contexto locativo, con un CLOC que precede o sigue. 
Los ejemplos donde meterse sí aparece en un auténtico contexto incoativo carecen de connotación negativa y de un locativo (53-54). Se trata de un grupo bastante reducido de ejemplos en el corpus (un 13\%), donde meterse expresa la entrada en una carrera o trabajo (53a-b) o donde su significado equivale a la acción de 'dedicarse a algo', 'esforzarse por ello' o 'ahondar / implicarse' en una actividad cuyo progreso requiere una inversión de tiempo, concentración y esfuerzo (54a-b). En estos casos, meterse sigue vinculándose con su significado locativo original, relacionado con la idea de 'interioridad' (uno se mete y entra 'a fondo' en una actividad, trabajo o carrera), es decir, se interpreta con un significado similar a su variante locativa y metafórica (interior):

(56) Casals fue metiéndose en la investigación hasta convertirla en tesis doctoral. [Redes]

Así, atendiendo a la Tabla 15, la semántica de meterse parece restringirse a contextos negativos y/o locativos. Por el contrario, ponerse forma parte mayoritariamente de perífrasis neutras y puras, desprovistas de rasgos locativos o de cualquier connotación negativa. Por lo tanto, la aparente sinonimia entre las dos construcciones incoativas resulta ser solo parcial.

\section{BIBLIOGRAFÍA}

\subsection{Obras literarias}

Aparicio, J. (2016). Representación computacional de las perifrasis aspectuales: de la cognición a la computación. Barcelona: Universidad de Barcelona.

Aparicio, J., Coll-Florit, M. \& Castellón, I. (2014). "Perífrasis incoativas: aproximación cognitiva y estudio de corpus", Sintagma, 26, pp. 73-88.

Arppe, A. (2008). Univariate, bivariate and multivariate methods in corpus-based lexicography - a study of synonymy. Helsinki: University of Helsinki.

Baayen, R. H. (2008). Analyzing linguistic data. A practical introduction to statistics using $R$. Cambridge: Cambridge University Press.

Bosque, I. (2004). Redes. Diccionario combinatorio del español contemporáneo. Madrid: Ediciones SM.

Burnham, K. P. \& Anderson, D. R. (2002). Model selection and multimodel inference. A practical information-theoretic approach. New York: Springer.

Bybee, J. \& Torres Cacoullos, R. (2009). "The role of prefabs in grammaticization". En Corrigan R. et al. (dirs.). Formulaic Language. Vol I. Amsterdam / Philadelphia: John Benjamins, pp. 187-217.

Carrasco Gutiérrez, A. et al. (2006). Diccionario de perifrasis verbales. Madrid: Gredos.

Cohen, J. (1960). "A coefficient of agreement for nominal scales", Educational and Psychological Measurement, 20, pp. 37-46.

Comrie, B. (1976). Aspect. An introduction to the study of verbal aspect and related problems. Cambridge: Cambridge University Press.

Divjak, D. (2010). "Corpus-based evidence for an idiosyncratic aspect-modality relation in Russian". En Glynn D. \& K. Fischer (dirs.). Quantitative Methods in Cognitive Semantics. Corpus-Driven Approaches. Berlin: Mouton de Gruyter, pp. 305-330.

Enghels, R. (2007). Les modalités de perception visuelle et auditive. différences conceptuelles et répercussions sémantico-syntaxiques en espagnol et en français. Tübingen: Max Niemeyer Verlag.

Enghels, R. \& Jansegers, M. (2013). "On the cross-linguistic equivalence of sentir(e) in Romance languages. a contrastive study in semantics", Linguistics, 51, pp. 957-991. 
Fischer, K. (2010). "Quantitative Methods in Cognitive Semantics. Introduction to the volume". En Glynn D. \& K. Fischer (2010). Quantitative Methods in Cognitive Semantics. Corpus-Driven Approaches. Berlin: Mouton de Gruyter, pp. 43-59.

Fleiss, J. L. (1981). Statistical methods for rates and proportions. New York: John Wiley.

Fogsgaard, L. (2001). "Algunas perífrasis incoativas con $a+$ infinitivo", Estudios de Lingüística, 15, pp. 5-35.

- (2002). Algunas perifrasis aspectuales del español. Alicante: Universidad de Alicante.

Garachana Camarero, M. (2017). La gramática en la diacronía. La evolución de las perífrasis verbales modales en español. Madrid / Frankfurt am Main: Iberoamericana Vervuert.

García Fernández, L. (2012). Las perífrasis verbales en español. Barcelona: Castalia.

García González, J. (1992). Perifrasis verbales. Madrid: Sociedad General Española de Librería.

García-Miguel, J. M. (2015). "Transitivity and verb clases”. En Barrajón López E., J.L. Cifuentes Honrubia \& S. Rodríguez Rosique (dirs.). Verb Classes and Aspect. Amsterdam / Philadelphia: John Benjamins, pp. 288-311.

Gili Gaya, S. (1961). Curso superior de sintaxis española. Barcelona: Vox.

Glynn, D. (2010). "Testing the hypothesis. Objectivity and verification in usage-based Cognitive Semantics". En Glynn D. \& K. Fischer (2010). Quantitative Methods in Cognitive Semantics. Corpus-Driven Approaches. Berlin: Mouton de Gruyter, pp. 237-269.

Gómez Manzano, P. (1992). Perifrasis verbales con infinitivo (valores y usos en la lengua hablada). Madrid: UNED.

Gómez Torrego, L. (1988). Perifrasis verbales. Madrid: Arco/Libros.

- (1999). "Los verbos auxiliares. Las perífrasis verbales de infinitivo". En Bosque I. \& V. Demonte (dirs.). Gramática Descriptiva de la Lengua Española. Vol. II. Madrid: Espasa-Calpe, pp. 33233441 .

Grijelmo, A. (2000). La seducción de las palabras. Madrid: Taurus.

Grondelaers, S., Speelman, D. \& Geeraerts, D. (2002). "Regression on er. Statistical analysis of texts and language variation”. En Morin A. \& P. Sébillot (dirs.). 6èmes journées internationales d'analyse statistique des données textuelles (Saint-Malo. 13-15 de marzo de 2002). Rennes: Institut National de Recherche en Informatique et en Automatique, pp. 335-346.

Heylen, K. (2005). "A quantitative corpus study of German word order variation”. En Kepser S. \& M. Reis (dirs.). Linguistic Evidence. Empirical, theoretical and computational perspectives. Berlin / New York: Mouton de Gruyter, pp.241-264.

Hosmer, D. W. \& Lemeshow, S. (2000). Applied Logistic Regression. New York: John Wiley.

Klavan, J. (2014). "A multifactorial corpus analysis of grammatical synonymy. The Estonian adessive and adposition peal 'on'”. En Glynn D. \& J. A. Robinson (dirs.). Corpus Methods for Semantics. Quantitative studies in polysemy and synonymy. Amsterdam / Philadelphia: John Benjamins, pp. 253-278.

Lamiroy, B. (1999). “Auxiliaires, langues romanes et grammaticalization”, Langages, 135, pp. 33-46.

Landis, J. R. \& Koch, G. G. (1977). "The measurement of observer agreement for categorical data", Biometrics, 33(1), pp. 159-174.

Langacker, R. W. (1991). Foundations of Cognitive Grammar. Descriptive application. Vol. II. Stanford: Stanford University Press.

Levshina, N. (2015). How to do Linguistics with R. Data exploration and statistical analysis. Amsterdam / Philadelphia: John Benjamins.

Llorente Vigil, C. (1999). Las perifrasis verbales. Salamanca: Ediciones Colegio de España.

Lluïsa Hernanz, M. (1999). "El infinitivo". En Bosque I. \& V. Demonte (dirs.). Gramática Descriptiva de la Lengua Española. Vol. II. Madrid: Espasa-Calpe, pp. 2197-2356.

Lúcia Esteves, A. (2004). "Algunos apuntes sobre temporalidad y aspecto verbal en español", Caligrama. Revista de Estudos Românicos, 9, pp. 7-28. 
Mendikoetxea, A. (1999). "Construcciones inacusativas y pasivas”. En Bosque I. \& V. Demonte (dirs.). Gramática Descriptiva de la Lengua Española. Vol. II. Madrid: Espasa-Calpe, pp. 1576-1629.

Peeters, B. (1993). "Commencer et se mettre à. une description axiologico-conceptuelle", Langue française, 98 , pp. 24-47.

Roasto, R. (2013). El aspecto gramatical en la lengua española y estonia. Tesina de maestría no publicada. Tartu: Universidad de Tartu.

Rojo, G. (1990). "Relaciones entre temporalidad y aspecto en el verbo español". En Bosque I. (dir.). Tiempo y aspecto en español. Madrid: Cátedra, pp. 17-43.

Real Academia española -Asociación de Academias de la lengua española (RAE-ASALE) (2009). Nueva gramática de la lengua española. Vol. II. Madrid: Espasa-Calpe.

Saunier, E. (1996). Identité Lexicale et Régulation de la Variation Sémantique. Contribution à l'étude des emplois de mettre, prendre, passer et tenir. Paris: Université de Paris X - Nanterre.

- (1999). "Contribution à une étude de l'inchoation. se mettre à + inf". En Vogeleer S. et al. (dirs.). La modalité sous tous ses aspects. Amsterdam: Rodopi, pp. 259-288.

Slawomirski, J. (1983). "La posición del aspecto en el sistema verbal español”, Revista española de lingüística, 13(1), pp. 91-120.

Speelman, D. (2014). "Logistic regression. A confirmatory technique for comparisons in corpus linguistics”. En Glynn D. \& J.A. Robinson (dirs.). Corpus Methods for Semantics. Quantitative studies in polysemy and synonymy. Amsterdam / Philadelphia: John Benjamins, pp. 487-533.

Speelman, D. \& Geeraerts, D. (2009). "Causes for causatives. The case of Dutch 'doen' and 'laten"'. En Sanders T. \& E. Sweetser (dirs.). Causal Categories in Discourse and Cognition. Berlin: Mouton de Gruyter, pp. 173-204.

Szmrecsanyi, B. (2010). "The English genetive alternation in a cognitive sociolinguistics perspective". En Geeraerts, D., G. Kristiansen \& Y. Peirsman (dirs.). Advances in Cognitive Sociolinguistics. Berlin / New York: Mouton de Gruyter, pp. 141-166.

Torres Cacoullos, R. (2000). Grammaticization, Synchronic Variation, and Language Contact. A Study of Spanish Progressive '-ndo' Constructions. Amsterdam: John Benjamins.

Traugott, E. C. (2015). "Toward a coherent account of grammatical constructionalization". En Barðdal, J., E. Smirnova; L. Sommerer \& S. Gildea (dirs.). Diachronic Construction Grammar. Amsterdam: John Benjamins, pp. 51-79.

Verroens, F. (2011). La construction inchoative se mettre à. syntaxe, sémantique et grammaticalisation. Gent: Universiteit Gent.

Zeschel, A. (2010). "Exemplars and analogy. Semantic extension in constructional networks". En Glynn D. \& K. Fischer (dirs.). Quantitative methods in cognitive semantics. corpus-driven approaches. Berlin / New York: Mouton de Gruyter, pp. 201-219.

Zieliński, A. (2014). Las perifrasis de los verbos de movimiento en español medieval y clásico. Kraków: Wydawnictwo Uniwersytetu Jagiellońskiego.

Yllera, A. (1980). Sintaxis histórica del verbo español: Las perifrasis medievales. Zaragoza: Universidad de Zaragoza.

\subsection{Ejemplos de corpus}

\section{CORPES XXI}

CORPES XXI 1: Sánchez-Andrade, Cristina, Bueyes y rosas dormían, 2001

CORPES XXI 2: El Mundo, 2011

CORPES XXI 3: Calvo, Javier, El jardín colgante, 2012

CORPES XXI 4: Rodríguez, Sergio, Canto rodado, 2007

CORPES XXI 5: Parrondo, Jorge, Maldito seas, Roque Waterfall, 2002

CORPES XXI 6: Fortes, Susana, Esperando a Robert Capa, 2009 
¿PerírRasis cuasisinónimas? Una Regresión logística aplicada a Las incoativas eXPresadas Con Ponerse...

CORPES XXI 7: Guelbenzu, José María, El hermano pequeño, 2011

CORPES XXI 8: Lindo, Elvira, Una palabra tuya, 2005

CORPES XXI 9: Gopegui, Belén, El lado frío de la almohada, 2004

CORPES XXI 10: Etxebarria, Lucía, De Todo lo Visible y lo Invisible. Una novela sobre el amor y otras mentiras, 2001.

CORPES XXI 11: Boadella, Albert, Memorias de un bufón, 2001

CORPES XXI 12: Abad, Mercedes, Media docena de robos y un par de mentiras, 2009

CORPES XXI 13: Padial, Carlo, Dinero gratis, 2010

CORPES XXI 14: Pombo, Álvaro, La fortuna de Matilda Turpin, 2006

CORPES XXI 15: Royuela, Fernando, La pasión según las fieras, 2003

CORPES XXI 16: Emezetablog, 2005

CORPES XXI 17: Serrano, Virtudes, Pájaros en la cabeza. Teatro a partir del siglo XXI, 2011

CORPES XXI 18: La Razón, 2002

CORPES XXI 19: Vega, Coradino, El hijo del fut bolista, 2010

CORPES XXI 20: La Voz de Galicia, 2011

CORPES XXI 21: Martínez Ballesteros, Antonio, Doña Perfecta. Tres, número impar, 2009

CORPES XXI 22: La Opinión de Coruña, 2007

CORPES XXI 23: Rojano, Antonio, La decadencia en Varsovia, 2007

CORPES XXI 24: Molina Foix, Vicente, El hombre que vendió su propia cama, 2011

CORPES XXI 25: Nieva, Francisco, Argumentario clásico, 2001

CORPES XXI 26: Mayoral, Marina, Deseos, 2011

CORPES XXI 27: Buenos dias, RNE, Radio 1, oral, 2001

CORPES XXI 28: Fernández García, Jorge Juan, Más allá de google, 2008

CORPES XXI 29: Inaraja, Javier, ¡Lánzate ya!, 2010

CORPES XXI 30: Salvador Caja, Gregorio, El eje del compás, 2002

CORPES XXI 31: Beccaria, Lola, La luna en Jorge, 2001

CORPES XXI 32: Vidal- Folch, Ignacio, Noche sobre noche, 2009

CORPES XXI 33: Nieva, Francisco, Argumentario clásico, 2001

CORPES XXI 34: Mendoza, Eduardo, La aventura del tocador de señoras, 2001

CORPES XXI 35: Rupérez, Javier, El precio de una sombra, 2005

CORPES XXI 36: Lobato, Óscar, Centhceure, 2009

CORPES XXI 37: Alonso de Santos, José Luis, Cuadros de amor y humor, al fresco, 2006 